\title{
Autonomous vehicles: challenges, opportunities, and future implications for transportation policies
}

\author{
Saeed Asadi Bagloee ${ }^{1} \cdot$ Madjid Tavana $^{2,3} \cdot$ Mohsen Asadi $^{4} \cdot$ Tracey Oliver $^{5}$
}

Received: 9 May 2016/Revised: 8 July 2016/Accepted: 8 August 2016/Published online: 29 August 2016

(c) The Author(s) 2016. This article is published with open access at Springerlink.com

\begin{abstract}
This study investigates the challenges and opportunities pertaining to transportation policies that may arise as a result of emerging autonomous vehicle (AV) technologies. AV technologies can decrease the transportation cost and increase accessibility to low-income households and persons with mobility issues. This emerging technology also has far-reaching applications and implications beyond all current expectations. This paper provides a comprehensive review of the relevant literature and explores a broad spectrum of issues from safety to machine ethics. An indispensable part of a prospective AV development is communication over cars and infrastructure (connected vehicles). A major knowledge gap exists in AV
\end{abstract}

Madjid Tavana

tavana@lasalle.edu;

http://tavana.us

Saeed Asadi Bagloee

saeed.bagloee@unimelb.edu.au

Mohsen Asadi

mohsenasadibagloee@yahoo.com.au

Tracey Oliver

tracey@gricelegal.com.au

1 Smart Cities Transport Group, Department of Infrastructure Engineering, Melbourne School of Engineering, The University of Melbourne, Parkville, VIC, Australia

2 Business Systems and Analytics Department, Distinguished Chair of Business Analytics, La Salle University, Philadelphia, PA 19141, USA

3 Business Information Systems Department, Faculty of Business Administration and Economics, University of Paderborn, 33098 Paderborn, Germany

4 Department of Civil and Environmental Engineering, Kharazmi University, Tehran, Iran

5 Grice Legal, Balwyn, Melbourne, VIC, Australia technology with respect to routing behaviors. Connectedvehicle technology provides a great opportunity to implement an efficient and intelligent routing system. To this end, we propose a conceptual navigation model based on a fleet of AVs that are centrally dispatched over a network seeking system optimization. This study contributes to the literature on two fronts: (i) it attempts to shed light on future opportunities as well as possible hurdles associated with AV technology; and (ii) it conceptualizes a navigation model for the AV which leads to highly efficient traffic circulations.

Keywords Autonomous vehicle Connected vehicle . Vehicle navigation · System optimality · Intelligent transportation system

\section{Introduction}

New technologies in communication and robotics have had a substantial influence on our daily lifestyle of which transportation is no exception. These technologies have given rise to the prospect of autonomous vehicle (AV) technology which aims to reduce crashes, energy consumption, pollution, and congestion while at the same time increasing transport accessibility. Although the idea of driverless vehicles has been around for decades, the exorbitant costs have hindered large-scale production [1]. Nevertheless, there has been an acceleration in the research and development efforts in the last decade to bring the idea of the AV to fruition. For example, the advent of the Google car brought AVs to the spotlight [2,3]. Moreover, the automotive industry spends around $€ 77$ billion worldwide on $R \& D$ in order to nurture innovation and to stay competitive $[4,5]$. 


\section{Traffic Ahead Many carmakers are developing prototype vehicles that} are capable of driving autonomously in certain situations. The technology is likely to hit the road around 2020.

\begin{tabular}{|c|c|c|c|c|c|}
\hline & BMW & Mercedes-Benz & Nissan & Google & General Motors \\
\hline VEHICLE & $\begin{array}{l}5 \text { Series } \\
\text { (modified) }\end{array}$ & $\begin{array}{l}\text { S } 500 \text { Intelligent } \\
\text { Drive Research } \\
\text { Vehicle }\end{array}$ & $\begin{array}{l}\text { Leaf EV } \\
\text { (modified) }\end{array}$ & $\begin{array}{l}\text { Prius and Lexus } \\
\text { (modified) }\end{array}$ & $\begin{array}{l}\text { Cadillac SRX } \\
\text { (modified) }\end{array}$ \\
\hline $\begin{array}{l}\text { KEY } \\
\text { TECHNOLOGIES }\end{array}$ & $\begin{array}{l}\text { Video camera tracks } \\
\text { lane markings and } \\
\text { reads road signs } \\
\text { Radar sensors detect } \\
\text { objects ahead } \\
\text { Side laser acanners } \\
\text { Ultrasonic sensors } \\
\text { Differential GPS } \\
\text { Very accurate map }\end{array}$ & $\begin{array}{l}\text { Stereo camera sees } \\
\text { objects ahead in 3-D } \\
\text { Additional cameras } \\
\text { read road signs and } \\
\text { detect traffic lights } \\
\text { Short- and long- } \\
\text { range radar } \\
\text { Infrared camera } \\
\text { Ultrasonic sensors }\end{array}$ & $\begin{array}{l}\text { Front and side radar } \\
\text { Camera } \\
\text { Front, rear, and side } \\
\text { laser scanners } \\
\text { Four wide-angle } \\
\text { cameras show the } \\
\text { driver the car's } \\
\text { surroundings }\end{array}$ & $\begin{array}{l}\text { LIDAR on the roof } \\
\text { detects objects } \\
\text { around the car in 3-D } \\
\text { Camera helps } \\
\text { detect objects } \\
\text { Front and side radar } \\
\text { Intertial measuring } \\
\text { unit tracks position } \\
\text { Wheel encoder } \\
\text { tracks movement } \\
\text { Very accurate map }\end{array}$ & $\begin{array}{l}\text { Several laser sensors } \\
\text { Radar } \\
\text { Differential GPS } \\
\text { Cameras } \\
\text { Very accurate map }\end{array}$ \\
\hline
\end{tabular}

Fig. 1 Expected specification of autonomous vehicles by the year 2020 (courtesy [12])

The rapid development of communication technology and the need to cater to the aging population in developed countries has potentially made AVs a necessity and a vital business paradigm [6]. In light of looming new ideas and technologies such as social networks, smart phones, and AVs, some scholars have emphatically warned that the landscape of transportation is rapidly changing [7-9]. An example is Uber which is sweeping cities to the extent that taxi companies are struggling to retain business and to remain competitive. Manyika et al. [10] includes vehicle automation on the list of the top ten disruptive technologies of the future.

As a result of fierce competition among car manufacturers, the year 2020 has been slated as a horizon year to offer commercial AVs to the general market $[1,11]$. Figure 1 provides an overview of the competition between the giant car makers [12]. Perhaps, the middle of the current century will be the maturity years of the AV market. Based on the deployment and adoption of previous smart vehicle technologies (like automatic transmission and hybridelectric drive) [13], the forecast is that AVs are expected to constitute around $50 \%$ of vehicle sales, $30 \%$ of vehicles, and $40 \%$ of all vehicle travel by 2040 . Therefore, it is incredibly important to be prepared for such eventualities and to understand the challenges that lie ahead while embracing and welcoming the ensuing opportunities.

The AV is associated with a variety of positive societal impacts such as a safer transport system, a lower cost of transport as well as enabling a modicum of mobility to the non-ambulatory and disabled as well as to those in lower income households. It is estimated that the direct societal value that will be created will be between 0.2 and 1.9 trillion dollars annually by 2025 [10]. Such positive impacts are the driving forces behind the emergence of $\mathrm{AV}$ technology, making it a viable, economic model in the near future and beyond.

Some believe that AVs must be viewed through a wideangled lens, as a multidisciplinary technology. Maddox et al. [14] depicted the AV in a figure with two additional components to ensure a successful working AV paradigm: "Connected" and "Big Data." Accordingly, the terms "Connected" or "Connected Vehicle" refer to the technologies that ensure communication between all contributing agents or stakeholders including pedestrians, authorities and vehicles, as well as infrastructure. ${ }^{1}$ Figure 2 depicts a conceptual representation of a connected system. The connected component will require a massive amount of data from a variety of sources. As a result, "Big Data" is a term used to highlight the importance of handling such an unprecedented amount of information for which special provisions including software and hardware will be required.

Each of these components is or has been the subject of extensive research in various fields. As such, AV technology could be considered at the crossroads of many disciplines such as transportation science, electrical

\footnotetext{
${ }^{1}$ Recent survey showed people perception of connected vehicle is wrong: by connected, they expect to get their smart phones connected to vehicles Schoettle and Sivak [15] A Survey of Public Opinion about Connected Vehicles in the US, the UK, and Australia.
} 


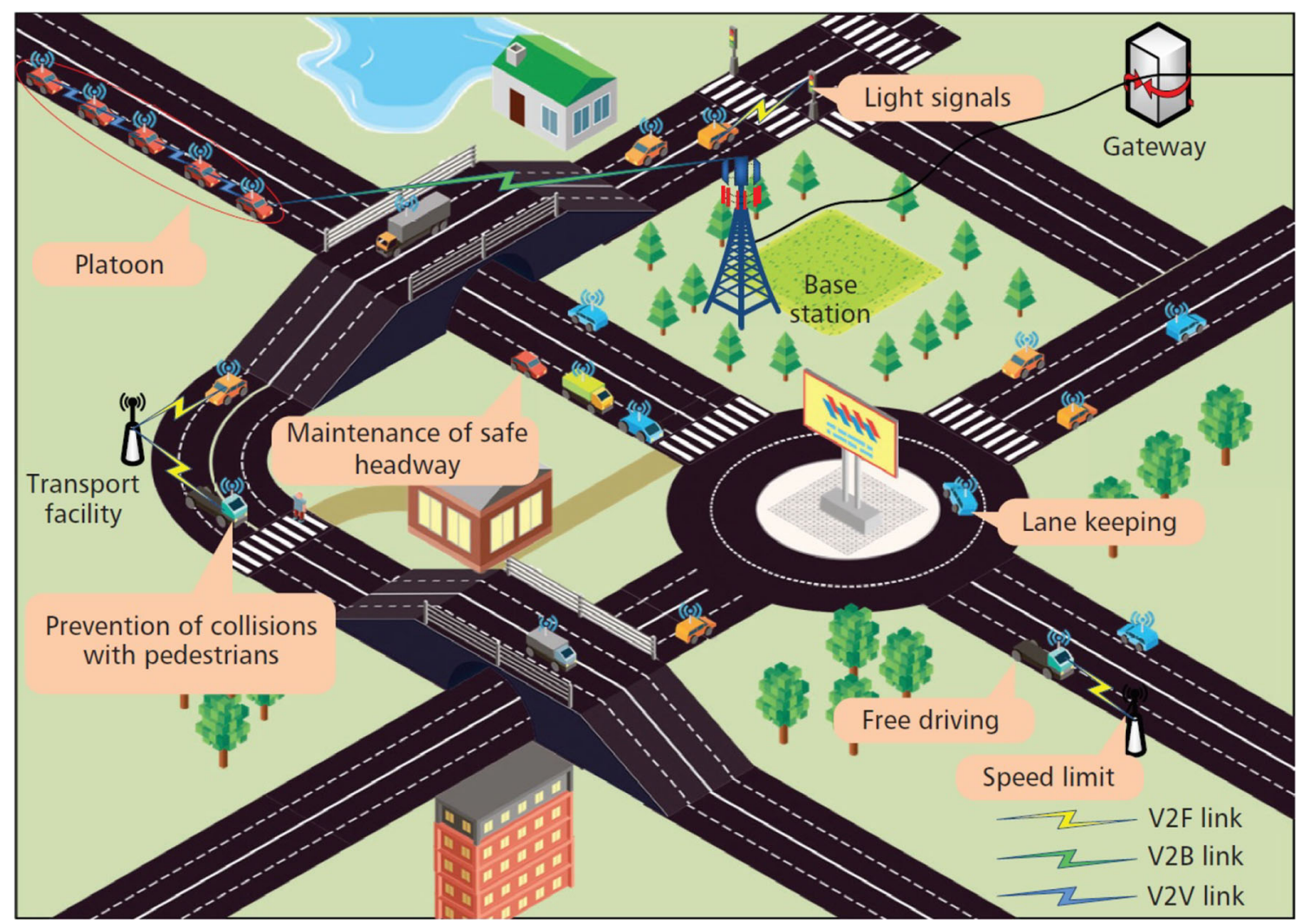

Fig. 2 A representation of connected vehicles and infrastructure (courtesy of [16])

engineering, information technology, software and hardware engineering, law, ethics, and philosophy. In this article, we look at the AV from a transportation point of view. We aim to shed light on the overarching implications of the AV for scholars, policy makers, planners, and practitioners involved in the transportation sector ${ }^{2}$.

In particular, we elaborate on features directly pertaining to transport planning such as safety, fuel consumption, road pricing and parking requirements, land use, and demand forecasting. We also touch on other related issues such as cybersecurity, law/regulation, as well as ethical concerns.

The aim is to highlight the opportunities and the challenges that may arise from the introduction and application of AVs. First we shall consider AV within the context of existing transportation systems and society at large, as well as define some related terminologies. We will then endeavor to show the impact of AVs for the short- and long-term future based on previous studies. In order to do this, we have reviewed over 118 references related to AV technology which have been published mainly in the past 5 years so as to provide a comprehensive and updated narrative.

\footnotetext{
${ }^{2}$ For a recent and comprehensive review, interested reader can consult with Anderson et al. [7].
}

Interestingly, the existing literature does not discuss the methods by which AVs find and determine their routes in the road networks (vehicle routing). Perhaps, it is presumed that AVs are not different to other cars in vehicle routing. As noted before, connected-vehicle technology is an indispensable part of a working AV scheme. Such (realtime) communication data may result in collaboration between the $\mathrm{AVs}$ directionality capabilities, leading to more efficient and intelligent path-finding (or traffic flow).

Real-time data (including travel time and incidents) can be processed and analyzed centrally in order to calculate and direct (or advise) AVs towards the best possible route. Thus, more sophisticated and reliable vehicle routing models can be developed for which we use the term vehicle navigation in this manuscript. Moreover, we will propose a navigation model based on the concepts of system optimality $[17,18]$ which seeks the best possible traffic pattern (minimizing the total travel time in the system).

In the remainder of the article, Sect. 2 contains a brief history of AVs; Sect. 3 defines the level of automation; Sect. 4 presents the operational principals of AVs; Sect. 5 discusses sensors and monitoring technologies which are essential to data collection and real-time communication; Sect. 6 is dedicated to the advantages and disadvantages of AVs; and Sect. 7 is devoted to the navigation model of AVs. Concluding remarks are also provided in Sect. 7. 


\section{A brief history of autonomous vehicles}

The first attempt towards driverless vehicles dates back as far as the early 1920s [19] and got momentum in the 1980s when researchers managed to develop automated highway systems [20, 21]. This paved the way for semiautonomous and autonomous vehicles to be connected to the highway infrastructure. Pioneer pilots of AVs were largely made in Germany and the U.S. during 1980 to 2000 [7, 22].

AVs are highly indebted to the extensive research on unmanned equipment made by the defense sector known as (DARPA) the U.S. Defense Advanced Research Projects Agency [23]. Google's driverless car gave huge publicities to the AV and attracted a pool of talent from several disciplines. As recently as July 2015, Google's driverless fleets logged over one million miles during which only 14 minor traffic accidents on public roads were recorded. In all cases, however, the AV was not at fault; rather, it was either being manually driven ${ }^{3}$ or the other driver was at fault [24]. Nevertheless, the first accident where the Google car was found at fault happened on Valentine's Day 2016, when the car struck the side of a public bus in the Silicon Valley city of Mountain View [25].

\section{Levels of automation}

It is important to note that the level of automation can vary from zero to full automation. NHTSA classifies vehicle automation in five levels [26]:

- No-Automation (Level 0) At all times, the driver has complete and sole command and control of the vehicle with respect to steering, braking, throttle and motive power.

- Function-specific automation (Level 1) Some specific control function(s) such as electronic stability control or precharged brakes is(are) automated.

- Combined function automation (Level 2) At least two main control functions such as adaptive cruise control ${ }^{4}$ in combination with lane centering ${ }^{5}$ are automated.

- Limited self-driving automation (Level 3) Under certain traffic or environmental conditions, the driver cedes full control of all safety-critical functions and relies heavily on the vehicle to watch for any changes in conditions

\footnotetext{
${ }^{3}$ In other words, the AV has ceased full/partial control to human being, and a person is in charge of the accident.

4 Autonomous cruise control (or adaptive cruise control or radar cruise control) is an optional cruise control system for road vehicles that automatically adjusts the vehicle speed to maintain a safe distance from vehicles ahead.

5 The lane centering application continuously controls the steering wheel in order to keep the vehicle at the lane center.
}

requiring transition to driver control. The driver will be required to resume control of the vehicle, but with sufficient transition time.

- Full self-driving automation (Level 4) The vehicle is intelligently designed to monitor roadway conditions and act solo, performing all safety-critical driving functions for an entire trip (a fully driverless level).

\section{How does the AV work?}

Generally speaking, AVs operate on a three-phase design known as "sense-plan-act" which is the premise of many robotic systems [27-29]. A substantial challenge for AVs rests in making sense of the complex and dynamic driving environment $[1,30]$. To this end, the AVs are equipped with a variety of sensors, camera, radars, etc., which obtains raw data and information from the surrounding environment. These data would then serve as input for software which would recommend the appropriate courses of action, such as acceleration, lane changing, and overtaking.

A combination of surveillance technologies is employed to cope with such a challenging job [31]. Typically, this task is solved by a combination of radar, Lidar ${ }^{6}$, and mono or stereo camera systems ${ }^{7}$. In Appendix 1, we will briefly introduce the monitoring technologies in AVs [7, 32, 33, 34].

\section{Advantages and disadvantages of AVs}

Although transportation is a means to foster the prosperity of societies, it inevitably is coupled with negative externalities such as pollution, accidents, and human casualties. There are a large number of studies estimating these costs in terms of human-driven vehicles [35, 36]. These costs differ from direct costs incurred such as the cost of petrol, vehicle maintenance, vehicle registration, and licensing or public transport tickets. The externality cost is a hidden cost imposed on society as a whole; it includes costs such as traffic congestion, accidents and environment degradation, as well as security. In general, AV technology is largely perceived to have the potential to substantially abate (if not eliminate) many of these existing negative externalities. In one estimate, these external costs can be as high as the fuel price which is imposed on society as a whole, including low-income individuals who are solely

\footnotetext{
${ }^{6}$ Lidar is a surveying technology that measures distance by illuminating a target with a laser light.

7 mono and stereo camera systems refer to one single camera and a series of coordinated cameras in place respectively.
} 
reliant on public transport [7]. AVs can also create additional benefits such as increasing accessibility and mobility and even improving land use. Although there could be significant disadvantages associated with $\mathrm{AVs}$, it is widely believed that these disadvantages are largely outweighed by the advantages. In the following section, we elaborate on the positives and negatives of $\mathrm{AVs}$.

\subsection{Safety and crashes}

The statistics for road accidents in the United States in 2010 is shocking: 32,999 killed, 3.9 million injured, and 24 million vehicles damaged, the tangible and intangible costs of which total $\$ 277$ billion [37]. This cost burden has a ripple effect, having an impact on productivity, medical costs, legal and court costs, workplace losses, emergency service costs, the congestion burden, insurance administration costs, and property damage. A downward trend in the number of crashes in the United States [38] is significantly indebted to the adoption of new technologies such as airbags, anti-lock brakes, electronic stability control, ${ }^{8}$ head-protection side air bags, and forward collision warnings [39, 40]. These are features that will be adopted in AV technology. In particular, some studies estimate the reduction of crashes could be as high as one-third if all vehicles are equipped with adaptive headlights, ${ }^{9}$ forward collision ${ }^{10}$ warnings, lane departure warnings ${ }^{11}$, and blind spot assistance ${ }^{12}$

\footnotetext{
${ }^{8}$ Electronic stability control, also referred to as electronic stability program or dynamic stability control, is a computerized technology that improves a vehicle's stability by detecting and reducing loss of traction (skidding).

9 Adaptive headlights are an active safety feature designed to make driving at night or in low-light conditions safer by increasing visibility around curves and over hills. When driving around a bend in the road, standard headlights continue to shine straight ahead, illuminating the side of the road and leaving the road ahead of you in the dark. Adaptive headlights, on the other hand, turn their beams according to your steering input so that the vehicle's actual path is lit up. See more at http://brainonboard.ca/safety_features/driver_assistance_technology_ adaptive_headlights.php\#sthash.og9DY4oN.dpuf.

${ }^{10}$ Forward Collision Warning (FCW) systems are based on camera or radar sensors monitoring the road ahead. They provide object recognition and detect relative speeds between a vehicle and objects in the road. If the closing speed represents a risk of an impending collision, drivers can be alerted through a number of warning methods. See more at http://www.trw.com/integrated_systems/driver_ assist_systems/forward_collision_warning.

11 A lane departure warning system is a mechanism designed to warn a driver when the vehicle begins to move out of its lane (unless a turn signal is on in that direction) on freeways and arterial roads. Lane warning/keeping systems are based on video sensors (mounted behind the windshield), or laser sensors (mounted on the front of the vehicle), or infrared sensors (mounted either behind the windshield).

12 A blind spot monitor is a vehicle-based sensor device that detects other vehicles located to the driver's side and rear. Warnings can be
}

$[39,40,41]$ which are attributed to Level 0 or Level 1 vehicle automation. Human error is blamed for more than ninety percent of crashes [42]. Therefore, AVs should be able to prevent an appreciable number of these crashes, in turn eliminating the vast majority of all traffic delays [7].

\subsection{Congestion}

Anderson et al. [7] have attributed three main factors related to AVs that affect congestion positively and sometimes negatively: (i) reducing traffic delay due to a reduction in vehicle crashes; (ii) enhancing vehicle throughput; and (iii) changes in the total vehicle-kilometertraveled (VKT). An anticipated reduction in vehicle crashes would result in fewer delays and, in turn, higher reliability of the transport system. The changes in VKT due to the advent of the AV remain unclear, though some researchers hold the view that VKT in fact would increase (known as the "rebound effect") [13]. For that, they speculate on a combination of factors such as additional VKT due to self-fueling and self-parking, increased use of AVs by those unable to drive ${ }^{13}$, an increased number of trips (both unoccupied and occupied), a shift away from public transport and longer commutes [43-45]. NHTSA came to the conclusion that the rebound rate will stabilize at $10 \%$ [7].

The fact that AVs are connected may also provide an opportunity to mitigate the congestion burden. Dresner and Stone [46] propose a reservation-based system for alleviating traffic congestion, specifically at intersections when the vehicles are connected. The results show that the reservation-based system designed for connected AVs can perform two to three times better than traffic lights. As a result, it can smoothly handle much more congested traffic conditions. Dresner and Stone [47] show that as the number of AVs on the road increases, traffic delays decrease towards the levels exhibited in their previous work. A similar conclusion was drawn by Fajardo et al. [48].

Consequently, it is crystal clear that AV technology will soon have a positive effect on traffic congestion abatement unless it induces additional demand that in turn might add further burden to an already congested network. The overall impact of the $\mathrm{AV}$ on traffic congestion has yet to be investigated.

\section{Footnote 12 continued}

visual, audible, vibrating or tactile. See more at https://en.wikipedia. org/wiki/Blind_spot_monitor.

${ }^{13}$ AVs may provide mobility for elderly and disabled people as well as adolescents who are unable to drive and which adds to the rebound demand as well. 


\subsection{Taxi and car ownership}

AV technologies can be conducive to driverless taxis or similar car-sharing schemes in which the cost of compensating cabdrivers' time and talent is excluded. As a result, driverless cabs are expected to become cheaper and which eventually may discourage car ownership.

The concept of driverless taxis is analogous to carsharing which is a thriving business model. AVs can boost car and ride sharing schemes as they can cater to multiple persons on demand [1]. Consequently, households may find driverless taxis more convenient and cheaper to hire than owning a vehicle. Furthermore, compared to car-sharing, driverless taxis should not be costlier. Given the fact that the driverless taxi obviates the need for annual fixed costs and maintenance normally associated with car-sharing as well as parking, it would provide even greater convenience. In actual fact, car-sharing has recently been found to lower VKT in the United States market [49]. Nevertheless, as previously mentioned, cheaper rides would be accompanied by new demands, especially from destitute (low-income) people who can now afford to either drive or to take a cab.

A recent analysis of US household data shows a significant reduction in vehicle ownership and an accompanying shift to vehicle sharing [50]. This reduction could be as high as $43 \%$-from 2.1 to 1.2 vehicles per household. Conversely, it is anticipated that this shift would inflate individual vehicle usage up to $75 \%$, from 11,661 to 20,406 miles per vehicle annually. (This increase in mileage does not factor in the additional miles generated during each "return-to-home" trip.)

All in all, AVs possess great potential to lower many costs associated with private modes as they are likely to instigate more trips, resulting in growth in VKT. AVs may also instigate an emergence in driverless taxis for which the ultimate effect on VKT is still unclear.

\subsection{AV and electric vehicles}

Environmental concerns, together with higher oil prices in the last decade have been the driving forces behind the emergence of Electric vehicle (EV) technology. The EV suffers from some operational drawbacks including a distance-traveling capacity limited to the size and durability of the batteries. It limits the EV to short-range travel and can make the process of finding charging stations a matter of constant anxiety [51].

In this context, one can find natural and organic synergy between shared AV fleets and EV technology: a fleet of $\mathrm{AVs}$ can resolve the practical limitations of EVs including travel range anxiety, access to charging infrastructure, and charging time management $[52,51]$.
Chen [53] has shown that fleet-managed AVs relieve such concerns based on real-time travel demand and established charging-station locations. Their financial analysis suggests that the combined cost of charging infrastructure, vehicle capital and maintenance, electricity, insurance, and registration for a fleet of $\mathrm{AVs}$ ranges from $\$ 0.42$ to $\$ 0.49$ per occupied mile traveled. Therefore, shared AV service can be offered at the equivalent per-mile cost of private vehicle ownership for low-mileage households. As such, automated electric cars will likely be competitive with current manually driven car-sharing services and significantly less expensive than on-demand driver-operated transportation services.

\subsection{Roads' capacity}

AV technologies provide finely tuned acceleration-braking maneuvers at all times while constantly and tirelessly monitoring the surrounding traffic environment. Therefore, $\mathrm{AVs}$ are able to cruise at higher speeds while maintaining shorter distances (lower headways). Semiautonomous vehicles equipped with Adaptive Cruise Control (ACC) have already shown such a promising function [54]. Lower headways by a queue of AVs will not compromise safety, and hence, we are likely to see a platooning of AVs. As a result, the throughput of the roads (or capacity) will significantly increase-some studies have estimated by up to 5 times [55]. In some studies, the fact that AVs are connected has been exploited in signal control which has resulted in much less delay at signals or equivalently higher road capacity [46-48].

\subsection{Congestion pricing}

As discussed earlier, the advanced technologies of AVs are supposed to provide an easing of traffic circulation and lowering of travel costs which in turn may induce additional travel demand. Such a demand can be seen as both a threat and an opportunity. The threat arises from the fact that the additional travel demand may worsen traffic congestion. The additional demand is the result of additional investment (AVs) injected into the transport system. Such concerns are becoming serious. For instance, researchers at Delft University in the Netherlands have advised the Dutch government to take measures (e.g., travel demand management) to curb the growth of travel and subsequent externalities of the impending AV technologies [56].

If one intends to maintain demand at the same levels as prior to the emergence of $\mathrm{AVs}$, then there is a legitimate opportunity to tap into the induced demand by means of congestion pricing. The pricing can be set to the level at which the induced demand dissipates. Congestion pricing 
is currently an active area of research [57]. The high level of communication technologies among AVs can greatly streamline any sort of pricing schemes, such as distancebased charging and dynamic pricing schemes.

\subsection{Value of time}

AVs release drivers from engaging in the physical and mental actions associated with driving, allowing them to utilize this time on other productive activities en-route. As a result, AVs further reduce the opportunity cost of travel in terms of the saved value of time pertaining to off-wheel activities [7].

\subsection{Land use}

AVs may have a profound and prolonged impact on the land-use pattern. The value of land increases proportionally with its proximity to the central city where job opportunities exist in many industries such as banking, financial markets, and many other service areas. Proximity is manifested by transportation. The advent of automobiles in the beginning of the 20th century resulted in the emergence of suburbs. The relation between AVs and land use is both complicated and somehow paradoxical. In one scenario, the introduction of $\mathrm{AVs}$ could invigorate a trend towards even more dispersed and low-density land-use patterns surrounding metropolitan regions. In other words, AVs may result in the further growth of suburbs and may even push further into exurb areas. In the completely opposite scenario, AV technology obviates the acute need for parking spaces meaning parking space in the heart of cities can be freed up for other usage. Therefore, AVs could end up stimulating urban growth in central districts, adding to the density of CBDs. It is important to note that parking facilities monopolize a big chunk of space in CBDs. Shoup [58] estimated that the total area dedicated to parking space is on average equivalent to about $31 \%$ of district areas.

In summary, the long-term expectation with the adoption of level $4 \mathrm{AVs}$ is that one would likely see denser urban cores, more buildings and fewer parking spaces. At the same time, AVs could lead to even greater dispersion of low-density development in metropolitan fringe areas given the ability of owners to engage in other activities while vehicles pilot themselves [7].

\subsection{Developing countries}

Third world countries struggle with a lack of transportation infrastructure, such as roads, bridges, and public transport, which is impeding their economic development. Adoption of AVs by these developing countries may spare them the costs associated with expanding capital-intensive infrastructure. A similar paradigm was seen when developing countries leap-frogged over to mobile phone technology which exempted them from expensive landline infrastructure $[7,59]$.

\subsection{Environment (energy and emission)}

Anderson et al. [7] have pointed out three factors upon which the impact of AVs on the environment would be either positive or negative:

- fuel efficiency of AVs,

- carbon-intensity and life-cycle emissions of the fossil fuel used to power AVs, and

- total change in VKT resulting from the use of AVs.

We have previously discussed VKT. In the next Section, we will elaborate on the fuel consumption and efficiency of AVs.

Regardless of the emergence of AVs, advances in vehicle design and engine efficiency have substantially decreased fuel consumption. In one estimation for passenger cars, fuel consumption was almost halved compared to the figures seen 30 years ago [60]. The adoption of AV technology even at Levels 1, 2, and 3 will lead to optimized driving and technology, also called eco-driving. Examples of some basic technologies that result in eco-driving are cruise control and smooth and gradual acceleration and deceleration. Eco-driving is proving to enhance fuel economy by $4 \%$ to $10 \%$ [61]. More optimistic predictions have envisaged an increase in fuel efficiency of up to $39 \%$ [62]. We have also previously discussed that AVs may lead to a higher travel capacity and a reduction in fuel wastage during times of traffic congestion.

AVs also provide an opportunity for vehicles to communicate their maneuvers and actions with each other which may reduce idle time, improving both traffic and drive-cycle efficiencies [7]. Furthermore, a platoon of closely spaced AVs that stops or slows down less often will resemble a train. The result is expected to result in lower peak speeds (improving fuel economy) but higher effective speeds (improving travel time) [63, 64].

From a completely different perspective, the increased level of safety of AVs may lead to lightweight vehicles from car manufacturers. In fact, safety efforts are being directed towards accident avoidance and away from oldfashioned crashworthiness cars. Therefore, light vehicles are promising by-products of $\mathrm{AV}$ technology which in turn greatly contributes to less fuel consumption. For conventional vehicles, up to $20 \%$ of the weight is attributed to safety-related features [61]. As an engineering rule-ofthumb, a 10-percent reduction in weight can lead to a 6- to 7 -percent reduction in fuel consumption [7, 65, 66, 67]). 
Turning to electric cars (from fossil-based cars) also brings added-value to fuel efficiency. It has been proven that the efficiency of the transformation in fossil-based cars versus electric cars is $1-3$ [7].

\subsection{Demand forecasting}

As previously discussed, the implications and applications of AV technology are overshadowed by uncertainties. One key concern of car manufacturers, regulation authorities, and, to some extent, academic scholars is to forecast the future demand of AVs. A recent and comprehensive review on the subject was presented by Bansal and Kockelman [68]. These predictions were based on the extrapolation of trends derived from previous vehicle technologies, expert opinions, and forecasts of supply-side variables with very little emphasis on the underlying assumptions behind these predictions.

As noted earlier, [13] foresees $50 \%$ of the worldwide car market being attributed to AVs by 2040 . According to one estimate [69], the market share of Levels 2 and 3 automated vehicles will total some USD 87 billion. These estimations or predictions vary substantially. Other studies take a much more optimistic view on the matter [see the discussion provided by Bansal and Kockelman [68]].

It is safe to state that given the ongoing investment in $\mathrm{AV}$ technology by the giant car manufacturers, the car market could soon be supplied by first generation AVs. How large this move would be is difficult to predict; however, it is likely to be significant enough to warrant the undivided attention of those involved in the planning phase.

In the preceding section, we covered themes directly related to the transportation policies. The AV however has far-reaching implications. In Appendix 2, we discuss some additional advantages and disadvantages of AVs including machine ethics, cybersecurity, and laws and regulation.

\section{AV navigation model ${ }^{14}$}

It is a matter of when AVs will be seen in the road network, and not if. Thus, they are an important part of transportation planning which requires the development of the

\footnotetext{
14 The navigation subject presented here is based on a macro view on how the AVs choose (or assign) routes. This subject differs from how an individual AV cruises through traffic by maneuvers, waving, acceleration/deceleration, etc., which is called "longitudinal control of an autonomous vehicle on the highway" (see Lefèvre et al. 2015. Autonomous car following: a learning-based approach, intelligent vehicles symposium (IV), 2015 IEEE. IEEE, pp. 920-926.). In such a domain, given a predefined route, the AV is closely controlled and driven through the traffic using learning-based methods which combine a driver model with model predictive control. The driver
}

appropriate models. The final stage of transportation modeling is the simulation of vehicle movements in the road network which is known as traffic assignment. To that end, there are two major simulations: micro and macro. In micro-simulation, detailed movements and behaviors of the individual vehicles are taken into account in any analysis. The early and basic features of automation (Levels 1 and 2) have prompted some scholars to include AV technologies into micro-simulations [70-73]. As noted above, the connectedness of AVs has been investigated in signal control policies which resulted in significant reductions in delay [46-48]. Other studies tend to extend the reach of the existing dynamic traffic assignment models to somehow include AVs [71, 74, 75]. Despite current computational technologies and current modeling knowledge, the scale of micro-simulation is limited to a portion of a city and not the entire city.

In contrast, macro-simulation easily encompasses large sized road networks. This section is devoted to a new macro-simulation to explicitly take a combination of AVs and non-AVs into consideration.

The fact that AVs must be connected-although this seems restrictive-can also be greatly exploited as an opportunity towards better vehicle routing. Vehicle routing refers to the way that vehicles seek their routes to get to their destinations. A common belief or model is based on the shortest path. In such a paradigm (also known as Wardropian principles), each vehicle "selfishly" chooses its own shortest possible path irrespective of other vehicles' choices. This leads to an equilibrium condition called User Equilibrium (UE), a situation where no vehicle can unilaterally find a shorter path. This selfishness will likely result in final traffic patterns known as non-cooperative. Since vehicles have no knowledge of the other vehicles' routes and destinations, the non-cooperative traffic pattern is the most widely recognized traffic model. In other words, when one is driving, he/she is completely unaware of neither where other vehicles are heading nor the routes that they are likely to take. In contrast, the cooperative traffic pattern assumes that the vehicles are aware of each other's destinations and routes. It has been shown both theoretically and empirically that the cooperative traffic pattern is more desirable than the non-cooperative traffic pattern, possibly by a factor of 2 [76, 77]. It has also been shown that if a number of selfish cars were to collaborate, it may still result in a traffic pattern much superior to the selfish, non-cooperative pattern [78-80].

Footnote 14 continued

model generates accelerations/deceleration which replicates the behavior of a human driver. The use of the controller ensures that some predefined safety constraints are satisfied. 
The literature still needs to broach the topic of the manner in which AVs find their routes in the road network (vehicle routing). Perhaps, it is presumed that AVs are no different than other cars in vehicle routing, that is, the selfish (or non-cooperative) traffic pattern. Connected vehicles bring about critical real-time traffic data (such as travel time and incident reports) which can then be used in a cooperative traffic fashion. In doing so, AV data can then be compiled and processed in traffic monitoring centers that in turn will recommend the most appropriate routes. That is, each vehicle will now literally be aware of the routes and destinations of other vehicles. Therefore, a more sophisticated, efficient, and informed vehicle routing system is attained. We refer to this as vehicle navigation.

In transport terminology, the cooperative pattern is also referred to as "SO: System Optimal (or System Equilibrium)" versus the non-cooperative, referred to as "UE," which are both the result of solving traffic assignment problems (TAP) [17, 18].

The complexity of the AVs' navigation rests on the fact that the AVs must share road space with non-AVs, resulting in mixed traffic patterns. Consider for a moment two types of vehicles: non-AVs and AVs. The non-AVs maintain their selfish behavior since there is no leverage to force them to seek the non-shortest path. In the meantime, we have the capability to enforce a vehicle navigation plan on the AVs. The challenge now is to find a model for a mixed traffic pattern that consists of both SO and UE traffic patterns. In such traffic patterns, a fleet of AVs are connected and they cooperatively find their route (vehicle navigation), while others are selfish drivers who only seek the shortest possible paths (vehicle routing).

The advent of ITS which has led to advanced traveler information systems (ATIS) such as radio and variable message signs has seen real-time traveler information become a reality [81, 82]. As such, in the mid-1990s, some scholars proposed tapping into this source of information to push for cooperative routing [83]. Nevertheless, the idea has yet to become a reality as it continues to struggle with a number of issues such as (i) the lack of enforcement strategy; and (ii) issues related to the veracity and reliability of the information, as well as restricted penetration of the ATIS.

In the following expositions, we provide a mathematical formulation for the mixed SO-UE traffic pattern cast as a multiclass traffic assignment problem.

\subsection{Vehicle navigation and routing formulations}

In the following description, we refer to cooperative and non-cooperative cars as AVs and selfish cars, respectively. Consider $G(N, A)$ a traffic network as a graph consisting of
$N, A$ sets of nodes and links, respectively, on which $D \subset N$ is a set of destinations.

Since a set of roads are defined and based on nodes (i.e., $A \subset N \times N$ ), we represent roads using a single character $a \in A$ as well as start and end nodes: $a=i j=(i, j) \in A$. At equilibrium conditions, both UE and SO traffic arrive at a stable situation in which no car changes its route. For the UE part, let $x_{a}$ denote a selfish traffic flow on road $a$ while $\bar{x}_{a}$ denotes the background traffic volume of the AVs on the respective road $a$. Therefore, the UE traffic pattern can be formulated as a non-linear programing problem $[17,18]$ as follows (throughout the manuscript, all terms are non-negative unless otherwise stated):

[UE-TAP]:

$$
\min z(x)=\sum_{a \in A} \int_{0}^{x_{a}} t_{a}\left(x_{a}+\bar{x}_{a}\right) \mathrm{d} x,
$$

s.t.

$\sum_{p} f_{p, i}^{k}=q_{i}^{k} \quad i \in N, k \in D$,

$f_{p, i}^{k} \geq 0 \quad p \in P_{i}^{k}, i \in N, k \in D$,

$x_{a}=\sum_{i} \sum_{k} \sum_{p} f_{p, i}^{k} \cdot \delta_{a, p, i}^{k} \quad a \in A, p \in P_{i}^{k}, i \in N, k \in D$,

where $z$ is the Beckmann objective function to be minimized; $q_{i}^{k}$ is the selfish travel demand from $i$ to $k ; f_{p, i}^{k}$ is the flow of selfish cars on path $p$ from $i$ to $k ; P_{i}^{k}$ is the set of all paths available to selfish cars from $i$ to $k$; and $\delta_{a, p, i}^{k}$ is the link-path incidence (1: if link $a$ belongs to path $p$ from $i$ to $k$ available to selfish cars, and 0 otherwise). Similarly at equilibrium, AVs volumes $\left(\bar{x}_{a}\right)$ in the context of background traffic of selfish volume $\left(x_{a}\right)$ can be formulated as follows $[17,18]$ :

[SO-TAP]:

$$
\begin{aligned}
& \min \quad z(\bar{x})=\sum_{a \in A} \bar{x}_{a} \cdot \bar{t}_{a}\left(\bar{x}_{a}+x_{a}\right) \\
& \sum_{p} \bar{f}_{\bar{p}, i}^{k}=\bar{q}_{i}^{k} \quad i \in N, k \in D \\
& \bar{f}_{\bar{p}, i}^{k} \geq 0 \quad p \in P_{i}^{k}, i \in N, k \in D \\
& \bar{x}_{a}=\sum_{i} \sum_{k} \sum_{p} f_{p, i}^{k} \cdot \delta_{a, p, i}^{k} \quad a \in A, p \in P_{i}^{k}, i \in N, k \in D
\end{aligned}
$$

The notations are similar as the bar on top of the terms represents the AVs. Both AVs and selfish travel demand a share of the same network $(a \in A)$. It is important to 
highlight the difference of the objective functions: while the UE-TAP is based on the Beckmann formulation (Eq. 1), the SO-TAP is based on the total travel time spent in the network (Eq. 5).

A plethora of methods have been proposed to solve the UE-TAP efficiently. As such, one easy way to solve a SOTAP is to transform it to a UE-TAP. To do so, one simply needs to replace the delay function $\bar{t}_{a}\left(\bar{x}_{a}+x_{a}\right)$ with the marginal delay function: $\bar{t}_{a}\left(\bar{x}_{a}+x_{a}\right)=\bar{x}_{a} . \partial \bar{t}_{a}$ $\left(\bar{x}_{a}+x_{a}\right) / \partial \bar{x}_{a}$. Therefore, both UE-TAP and SO-TAP can be combined as a single UE-TAP but with two different delay functions and travel demand matrices. This approach is very common in transportation modeling and is known as a multiclass traffic assignment problem (MC-TAP). Solving a MC-TAP is computationally more intensive than a single class TAP for which a variety of methods such as Variational Inequality, Complementarity Method, FixedPoints and Entropy Maximization, as well as origin-based (or bush based) methods have been proposed [84-94].

The SO traffic pattern is the most desirable traffic pattern. In this pattern, the total travel time spent on the network (i.e., the network performance index) is minimized. In reality, people follow the shortest path which leads to the traffic pattern known as UE. In terms of the total travel time spent on the network (also an index for congestion levels), the gap between UE and SO can reach as high as 2.15. In other words, one can significantly improve the congestion level by up to 2.15 times by enforcing a SO pattern rather than a UE traffic pattern. This gap has been the motive for a variety of traffic management (or control) measures and policies such as parking planning, congestion pricing, and ramp metering. The advent of AVs can also be added to these schemes.
In what follows, we elaborate on mixed SO-UE traffic flow using Braess' famous network.

\subsection{Mixed SO-UE traffic flow on Braess' example}

Braess [95] in his influential paper proved that adding more capacity to the road network (like constructing a new road) sometimes adversely worsens the traffic circulation, a phenomena coined after Braess as the Braess Paradox. Figure 3 shows a situation in which adding road 5 counterexpectedly deteriorates the current traffic flow.

The occurrence of $\mathrm{BP}$ dwells right at the point that people follow UE rather than SO. Otherwise, no one would use road " 5 " provided in the network of Fig. $3 \mathrm{~b}$ and hence no Braess paradox. In order to show the advantage of mixed SO and UE, we dispatch a portion of the travel demand of the above Braess network (Fig. 3) as AVs following SO. Given the delay functions provided in Fig. 3, the UE and SO traffic flows can be formulated as follows (note $\mathrm{x}$ and $\mathrm{y}$ represents $\mathrm{UE}$ and SO (or AVs) traffic volumes on the links):

UE flow:

$$
\begin{aligned}
& \min \int_{0}^{x_{1}}\left(50+x_{1}+y_{1}\right) \mathrm{d} x+\int_{0}^{x_{2}}\left(50+x_{2}+y_{2}\right) \mathrm{d} x \\
& \quad+\int_{0}^{x_{3}} 10 \cdot\left(x_{3}+y_{3}\right) \mathrm{d} x+\int_{0}^{x_{4}} 10 \cdot\left(x_{4}+y_{4}\right) \mathrm{d} x \\
& \quad+\int_{0}^{x_{5}}\left(10+x_{5}+y_{5}\right) \mathrm{d} x, \\
& x_{1}+x_{3}=(1-\rho) \cdot 6, \\
& x_{2}+x_{4}=(1-\rho) \cdot 6, \\
& x_{1}+x_{5}=x_{4},
\end{aligned}
$$

SO flow:

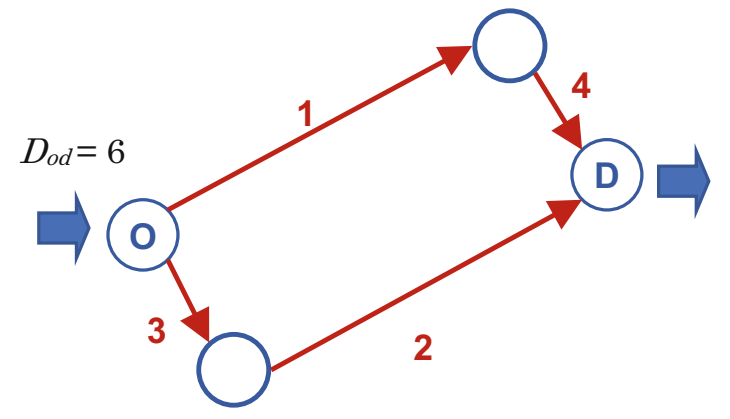

(a) Without Braess Paradox

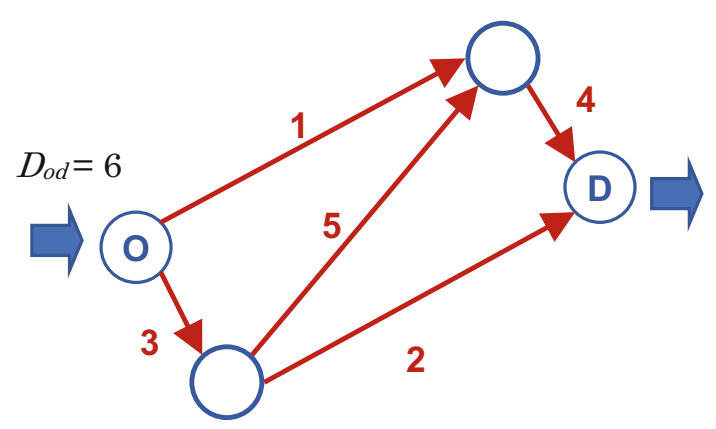

(b) With Braess Paradox

Delay Functions: $t_{1}(x)=t_{2}(x)=x+50 ; t_{3}(x)=t_{4}(x)=10 x ; t_{5}(x)=x+10$

Fig. 3 Braess Paradox where removing link 5 yields a better traffic flow 


$$
\begin{aligned}
& \min \left(50+x_{1}+y_{1}\right) y_{1}+\left(50+x_{2}+y_{2}\right) y_{2} \\
& \quad+10 \cdot\left(x_{3}+y_{3}\right) y_{3}+10 \cdot\left(x_{4}+y_{4}\right) y_{4}+\left(10+x_{5}+y_{5}\right) y_{5}
\end{aligned}
$$

$y_{1}+y_{3}=\rho \cdot 6$,

$y_{2}+y_{4}=\rho \cdot 6$,

$y_{1}+y_{5}=y_{4}$,

where $\rho, 0 \leq \rho \leq 1$ is a parameter representing the share of AVs out of the total demand. The above problems can be combined to become a non-linear programing problem

(NLP) as follows:

mixed UE-SO:

$\min (9)+(13)$, s.t. (10), (11), (12), (14), (15), (16).
The above NLP is encoded in GAMS [96] a leading optimization software. The GAMS code is made available in Fig. 4 to other scholars to be used in further studies.

We vary "rho" gradually from 0 [all UE, zero SO (AVs)] to 1 [zero $\mathrm{UE}$, all $\mathrm{SO}(\mathrm{AVs})$ ] to monitor the changes in the traffic flow when the share of SO increases. Table 1 presents the numerical results including UE and SO traffic volumes, whereas Table 2 provides travel times of the links as well as the total travel time in the network. It is obvious that as the share of SO (AVs) increases the total travel time (last column of Table 2) decreases until $\rho=0.5$, at which the total travel time remains the same at 498. This can also be seen by tracking down the changes in $x_{5}$ the traffic volume of link " 5 " which is a BP contaminated link. The value of $x_{5}$ decreases to zero and remains steady from there

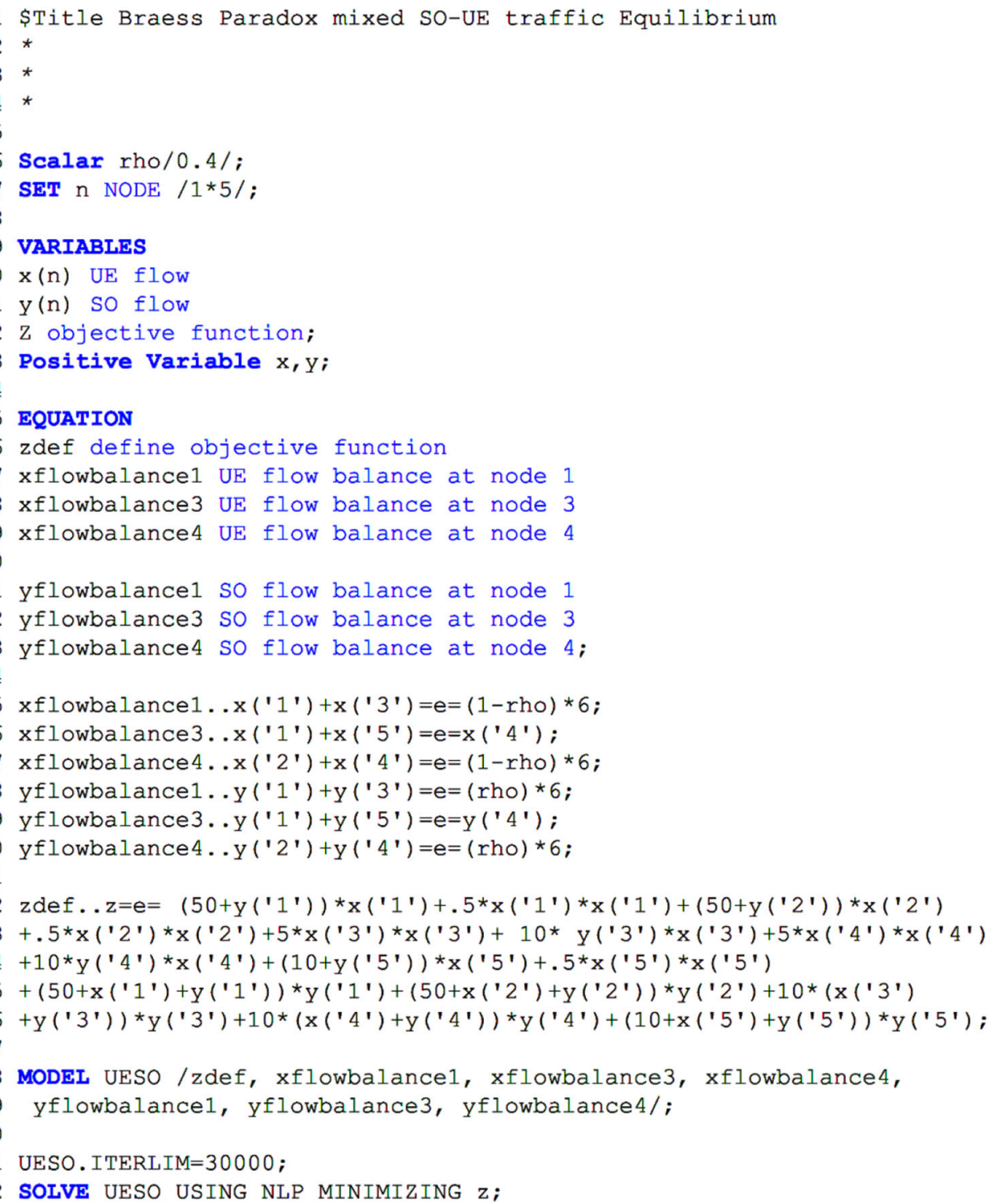

Fig. 4 GAMS code to solve mixed SO-UE traffic flow for Braess' example 
Table 1 Braess network example-mixed SO-UE traffic volume on the links

\begin{tabular}{|c|c|c|c|c|c|c|c|c|c|c|}
\hline \multirow[t]{2}{*}{$\rho$} & \multicolumn{5}{|c|}{ UE traffic volume $(x)$} & \multicolumn{5}{|c|}{ SO traffic volume $(y)$} \\
\hline & 1 & 2 & 3 & 4 & 5 & 1 & 2 & 3 & 4 & 5 \\
\hline 0 & 2 & 2 & 4 & 4 & 2 & 0 & 0 & 0 & 0 & 0 \\
\hline 10 & 2.508 & 1.308 & 2.892 & 4.092 & 1.585 & 0 & 0.6 & 0.6 & 0 & 0 \\
\hline 20 & 3.015 & 0.615 & 1.785 & 4.185 & 1.169 & 0 & 1.2 & 1.2 & 0 & 0 \\
\hline 30 & 3.517 & 0 & 0.683 & 4.2 & 0.683 & 0 & 1.8 & 1.8 & 0 & 0 \\
\hline 40 & 1.631 & 1.631 & 1.969 & 1.969 & 0.338 & 1.2 & 1.2 & 1.2 & 1.2 & 0 \\
\hline 50 & 1.5 & 1.5 & 1.5 & 1.5 & 0 & 1.5 & 1.5 & 1.5 & 1.5 & 0 \\
\hline 60 & 1.2 & 1.2 & 1.2 & 1.2 & 0 & 1.8 & 1.8 & 1.8 & 1.8 & 0 \\
\hline 70 & 0.9 & 0.9 & 0.9 & 0.9 & 0 & 2.1 & 2.1 & 2.1 & 2.1 & 0 \\
\hline 80 & 0.6 & 0.6 & 0.6 & 0.6 & 0 & 2.4 & 2.4 & 2.4 & 2.4 & 0 \\
\hline 90 & 0.3 & 0.3 & 0.3 & 0.3 & 0 & 2.7 & 2.7 & 2.7 & 2.7 & 0 \\
\hline 100 & 0 & 0 & 0 & 0 & 0 & 3 & 3 & 3 & 3 & 0 \\
\hline
\end{tabular}

Table 2 Braess network example-mixed SO-UE - travel time of the links and total travel time

\begin{tabular}{|c|c|c|c|c|c|c|c|c|c|c|c|}
\hline \multirow[t]{2}{*}{$\rho$} & \multicolumn{5}{|c|}{ Travel_time } & \multicolumn{5}{|c|}{ Travel_time $*(\mathrm{SO}+\mathrm{UE})$} & \multirow[t]{2}{*}{ Total travel time } \\
\hline & 1 & 2 & 3 & 4 & 5 & 1 & 2 & 3 & 4 & 5 & \\
\hline 0 & 52 & 52 & 40 & 40 & 12 & 104 & 104 & 160 & 160 & 24 & 552 \\
\hline 10 & 52.508 & 51.908 & 34.92 & 40.92 & 11.585 & 131.69 & 99.04 & 121.941 & 167.445 & 18.362 & 538.478 \\
\hline 20 & 53.015 & 51.815 & 29.85 & 41.85 & 11.169 & 159.84 & 94.044 & 89.102 & 175.142 & 13.057 & 531.185 \\
\hline 30 & 53.517 & 51.8 & 24.83 & 42 & 10.683 & 188.219 & 93.24 & 61.653 & 176.4 & 7.296 & 526.808 \\
\hline 40 & 52.831 & 52.831 & 31.69 & 31.69 & 10.338 & 149.565 & 149.565 & 100.426 & 100.426 & 3.494 & 503.476 \\
\hline 50 & 53 & 53 & 30 & 30 & 10 & 159 & 159 & 90 & 90 & 0 & 498 \\
\hline 60 & 53 & 53 & 30 & 30 & 10 & 159 & 159 & 90 & 90 & 0 & 498 \\
\hline 70 & 53 & 53 & 30 & 30 & 10 & 159 & 159 & 90 & 90 & 0 & 498 \\
\hline 80 & 53 & 53 & 30 & 30 & 10 & 159 & 159 & 90 & 90 & 0 & 498 \\
\hline 90 & 53 & 53 & 30 & 30 & 10 & 159 & 159 & 90 & 90 & 0 & 498 \\
\hline 100 & 53 & 53 & 30 & 30 & 10 & 159 & 159 & 90 & 90 & 0 & 498 \\
\hline
\end{tabular}

as $\rho$ decreases. In contrast, it is interesting to note that at any point of time (various values of $\rho$ ) the SO avoids the BP contaminated link " 5 ". Furthermore, from $\rho=0.5$ onward, the UE traffic flow finds no incentive to drive through link " 5 " as a bypass road which is the result of the presence of SO in the network.

\section{Conclusion}

AVs have been an active area of research for some decades but particularly in the past five years. The recent joint efforts by universities and manufacturers have brought $\mathrm{AVs}$ to near readiness. AVs are believed to considerably lower transportation costs. In one estimate, social AV impacts in terms of crash savings, travel time reduction, fuel efficiency, and parking benefits may be as much as
$\$ 2000$ per annum per AV and may be as high as $\$ 4000$ when comprehensive crash costs are accounted for [1]. The AV is still in the infancy stage. There is a considerable road to travel before maturity, implementation, and mass-market release are achieved.

The path is still problematic, facing several challenges. Perception of the environment remains the biggest challenge to reliable, smooth, and safe driving [7]. There is a long list of research questions covering a wide scope that will need to be addressed and answered, including but not limited to customer acceptance, societal impacts, communication technologies, ethical issues, planning, standards, and policy [7, 14]. Software challenges such as system security and integrity have also emerged as serious issues to be addressed. These in turn have a number of policy implications including the challenge for policymakers to streamline and regulate many diverse vehicles with 
different operating constraints. It is also of paramount importance for policymakers to ensure that drivers understand these vehicles' capabilities and can operate them safely. One of the challenges ahead is to connect several intelligent vehicles to each other and to the infrastructure which gives rise to the application of Big Data, a topic concerned with the processing and analysis of large datasets [33]. In this paper, we shed light on transport related themes that are directly or indirectly and positively and negatively affected by emerging AV technology. Examples are land use, safety, vehicle-kilometer-traveled, parking, variation of demand, and fuel consumption. We have also highlighted the huge potential of incorporating connected vehicles into current traffic networks, resulting in more efficient and smooth traffic circulation. To this end, we put forward the concept of vehicle navigation to solve the routing problems faced by AVs when integrated with nonAVs. We then proceeded to formulate a traffic assignment model for the combination of AVs and non-AVs which is a synergy of system optimal and user equilibrium conditions.

As expected and shown using the Braess example, centrally dispatching, a fleet of vehicles (the AVs in this case) following the system-optimal pattern can indeed improve overall traffic flow. In theory, the improvements may be as high as 2.15 times, which is astonishing. This fact should not go unnoticed in modern traffic planning and management practices. Therefore, AVs and SO navigation is without doubt a worthy thread of research and practice for scholars and practitioners alike.

In the near future, AVs will be an indispensable part of modern transport systems [97]. Furthermore, in light of such rapid changes in intelligent transportation systems, the education system must without question, align itself with these emerging technologies. Traffic engineering schools must reform their curricula to ensure that they cover more diverse subjects including communication technologies, software development, electrical engineering, and environmental and energy sustainability [97].

This paper-for the first time-provides a methodological framework to concurrently model AVs navigation as a SO traffic pattern with UE traffic patterns of conventional vehicles (non-AVs). Numerical applications using methods such as Variational Inequality, Complementarity, or fixed point are worthy of far more investigation. Simultaneously, providing an agent-based micro-simulation formulation for the integration of $\mathrm{AVs}$ and non-AVs following the SO and UE principles should be the subject of further studies. Such agent-based modeling can then be utilized in real-time traffic management.

Open Access This article is distributed under the terms of the Creative Commons Attribution 4.0 International License (http:// creativecommons.org/licenses/by/4.0/), which permits unrestricted use, distribution, and reproduction in any medium, provided you give appropriate credit to the original author(s) and the source, provide a link to the Creative Commons license, and indicate if changes were made.

\section{Appendix 1: Sensors and monitoring technologies}

Camera-based systems are inexpensive devices that can "see" and cover very long distances. The rich data collected from the cameras needs to be interpreted. This process is called image processing which is a fast developing research area [98]. Compared to the image processing capabilities of these camera-based systems, the human brain is much more sophisticated in terms of image processing and interpreting visual data [7, 98]. Furthermore, the cameras will require constant calibration subject to the road and weather conditions and this is still an active research thread in robotic science [99, 100].

Lidar ("light" and "radar"; also an acronym for Light Detection And Ranging) refers to a remote sensing technology to measure distance by illuminating an object with a laser beam and analyzing the reflected light and its time-offlight [101]. In order to acquire a 3D visualization of the environment, a set of Lidars is coupled and synchronized with rapidly rotating mirrors $[102,103]$. The main limitations of the Lidar system are their lack of coverage and range (unsuitable for long range or distance) and reflectivity issues. Unlike the camera-based system, Lidar is only functional for short ranges or distances and with certain materials. Although the cost of the Lidar system is relatively significant, it is on a downward trend [104], becoming cheaper and more efficient.

Radar (radio detection and ranging) is based on signals' time-of-flight to determine the distance from targets in the environment (similar to Lidar). In contrast to Lidar, however, radar systems transmit and receive radio waves, not laser beams, which results in a range of different limitations and advantages. The reflectivity limitations of radar are even more severe than those seen with Lidar; it is only able to detect metallic objects such as vehicles while objects such as pedestrians remain invisible to a radar sensor. Such shortcomings have been the subject of extensive research in the automotive radar field owing to the widespread use of radar in vehicles, especially in driver assistance systems [105, 106].

Ultrasonic, inspired by the ability of bats to navigate the darkness or of dolphins and whales underwater, is a detection system based on transmitting/receiving acoustic (sound) energy in the form of waves with a frequency above the human hearing range. Operation is similar to radar but high-frequency acoustic waves are sent and received. These sensors provide accurate short-range data 
(1-10 m). Given the relatively low cost, ultrasonic capabilities are instrumental in backup warning systems and parking assistance systems [7, 107, 108, 109].

Infrared sensors are largely employed in lane marking detection without the environmental limitations of cameras and lighting. Since their coverage range is limited to close distances, they are viewed capable in detecting lane departures [110]. Furthermore, infrared sensors are used in detecting pedestrians and bicycles, particularly at night [111].

Geographic Positioning Systems (GPS) are becoming an omnipresent device in everyday life and transportation as well as other industries. The GPS devices operate on signals from orbiting satellites to triangulate its position as global coordinates. These coordinates are then cross-referenced with the topography of the road network to pinpoint a vehicle's position on the road. GPS errors can still be large [112] — several meters in fact. The positioning errors grow rapidly when obstacles or terrain obscure the sky precluding GPS receivers from obtaining signals through a sufficient number of satellites. This is a genuine concern in the heart of the cities, where tall buildings create "urban canyons" in which GPS capabilities are severely limited [113, 114].

Inertial navigation systems (INS) are a navigation aid that employs accelerometers (motion sensors), gyroscopes (rotation sensors), and a computer to constantly calculate the position, velocity, and orientation (i.e., direction and speed of movement) of a moving target without any need for external references. GPS receivers can also be also coupled with INS to lower their positioning errors [115, 116].

The shortcomings of these sensors and devices are well known; hence, the usual practice is to develop suites of complementary sensors that are installed around the vehicle to avoid blind spots. Integration of GPS and INS is one such measure. Figure 5 shows a typical car equipped with sensors, camera and other devices.

Regardless of the effort, environmental challenges may result in malfunctions occurring in these monitoring devices and sensors. Given these challenges, the idea of vehicle-to-vehicle [117] communication (V2V), together with vehicle-to-infrastructure [118] communication (V2I) has been proposed. The idea is to share knowledge compiled from a fleet of connected vehicles and the infrastructure, leaving little or no room for error. The success of this idea relies on how this communication takes place. A plethora of studies have been devoted to developing communication standards better known as dedicated short-range communication (DSRC) [119]. Recently, the University of Michigan formed a consortium of industrial, government and academic partners to conduct a pilot study in the city of Ann Arbor [14]. As a result, this is still an evolving subject.

Furthermore, long before the idea of AVs was developed, the concept of "connected vehicles" (United States) or "cooperative ITS" (Europe) was known to the Intelligent Transport Studies (ITS) industry. These concepts

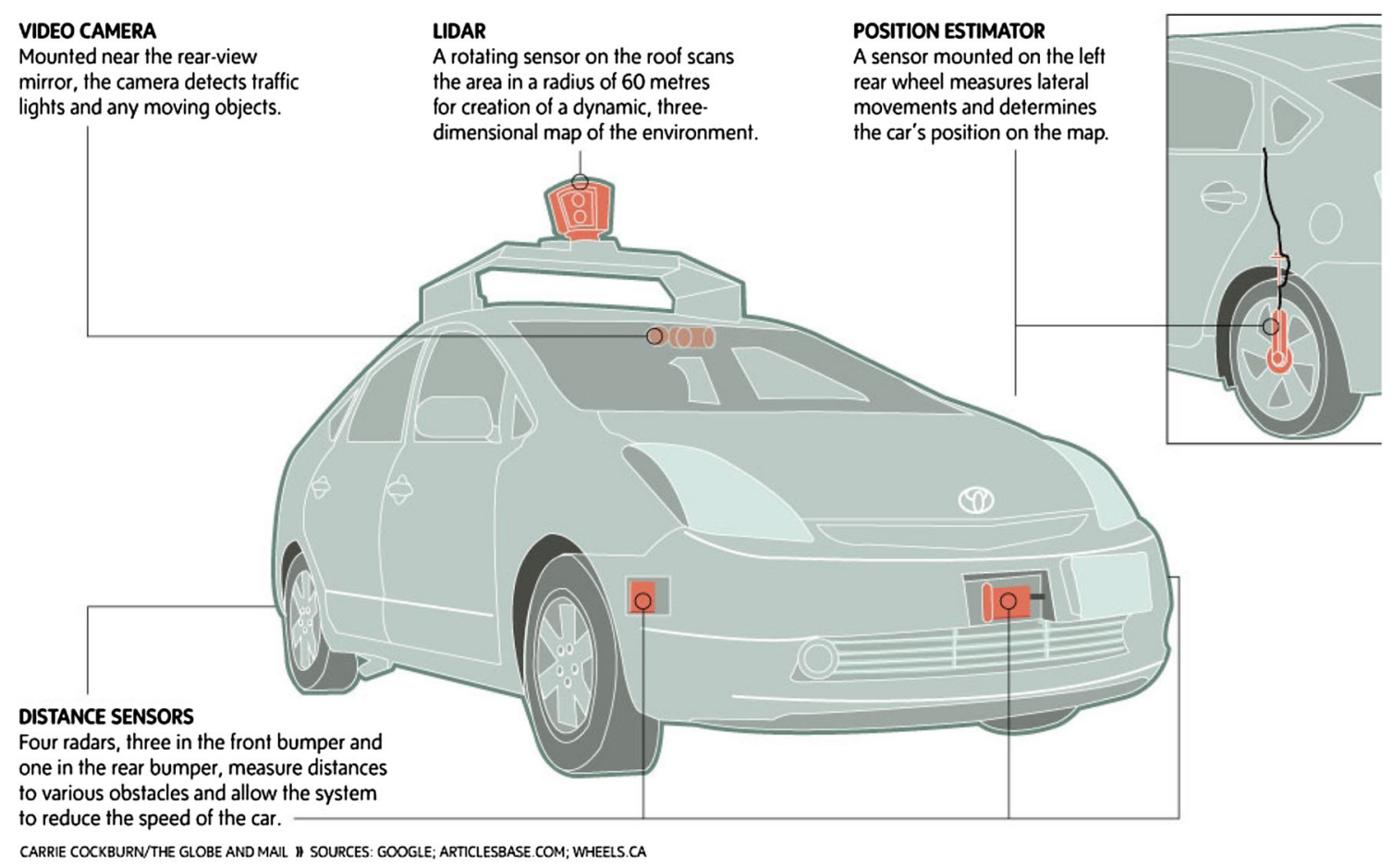

Fig. 5 Communication technologies (courtesy [27]) 
revolve around the communication and data sharing among vehicles $(\mathrm{V} 2 \mathrm{~V})$ and/or between vehicles and infrastructure $(\mathrm{V} 2 \mathrm{I} / \mathrm{I} 2 \mathrm{~V})$ with a view to streamlining the information needed to implement ITS applications. A recent study has shown that the separate threads of automated vehicles and cooperative ITS have not yet been thoroughly woven together [11]. Accordingly, this will be a fundamental step in the near future because the cooperative exchange of data will provide vital input to improve the performance and safety of the automation systems.

\section{Appendix 2: Additional Advantages and disadvantages of AVs}

Machine ethics As noted above, AVs are supposed to eradicate human error in crash situations and make the road safer. Nevertheless, the rate of crashes will not equate to zero. Firstly, AVs would still be dealing with non-AVs or occasionally human-driven AVs and secondly, irrespective of how complete the autonomous level is, pedestrians will always be present in any transport system. Therefore, AVs must be preprogrammed with various responses in crash conditions. Many ethical issues are encountered when considering how to preprogram $\mathrm{AVs}$ in the event of various crash scenarios. Let us discuss the ethical complexities using two such scenarios:

Scenario (1) Imagine an AV is on its way down the road when it suddenly encounters another car containing two occupants, which has proceeded through or run a red light. A fatal crash is inevitable. The AV has two options: (i) press the brake pedal and hit the guilty car; or (ii) turn the wheel to the road side and brake where there is a pedestrian waiting for a green light to cross the intersection. The dilemma is whether to kill one innocent person (the pedestrian) or the two persons in the offending vehicle (including the driver who knowingly ran the red light).

Scenario (2) Consider the same circumstances as in Scenario (1), but this time, the pedestrian has been removed from the equation. Now the AV has the choice to turn the wheel to the road side and collide with a lamp post. Unfortunately, the AV does not have comprehensive insurance; rather it only has third party insurance. The two options available to the AV are as follows: (i) Hit the car knowing that the damage will be compensated by the insurance of the offending vehicle. While the AV will be replaced, the human toll is two lives, yet there will be no liability placed upon the AV. Option (ii) is to hit the lamp post. While no lives will be lost, the offending vehicle will escape with no liability resulting in no compensation avenues open to the AV.

The ethical and legal aspects of AV technology are still evolving and have attracted interest from scholars from many different disciplines including philosophy and law. Recent reviews on research involving machine ethics and AV are provided by Kumfer [120] and Kumfer and Burgess [121].

Cybersecurity Since the beginning of 2012, rapid advances in cybercrime technology and techniques targeting infrastructure have resulted in an unprecedented rise in data breaches [122]. Despite the importance of cybersecurity of AV technology, there are issues that have not been raised in mainstream debate or research. It is important to understand that cyber threats exist on two frontiers: the operation of AVs themselves as ad-hoc vehicles and their communication capabilities as connected and/or cooperative automated vehicles.

In the former case (ad-hoc AV), for a single observation, there must be more than two detection sources that constantly approve the observations. It is called "sufficient redundancy" in data sources or we may also refer to it as "detection policy due diligence." In such cases, the attack can be diagnosed if only a minority of sources has been compromised. Accordingly, a robust data fusion system could potentially assist in identifying anomalous inputs produced by a cyberattack. In the latter case, the communication capabilities between AVs and its infrastructure provide additional information sources that can be used as extra tools to verify vehicle status and to confirm or confront attacks. Although the communication is itself an opportunity against the cyberattack, it can also provide attackers with additional opportunities to do harm. In any event, the systems should be designed to fail smoothly in the event of coordinated attacks across multiple sources.

In AVs, global navigation satellite systems (GNSS) hold a key role in positioning vehicles on an accurate map. Therefore, manipulating GNSS data could provoke erratic and inaccurate maneuvers which could in turn endanger passengers' lives. According to Petit and Shladover [11], an injection of fake messages and GNSS spoofing are the most dangerous attacks. It is important to note that the accuracy of civilian GPS receivers may be undermined by the United States military through a "selective availability and antispoofing module" (SAASM). The SAASM is employed by military GPS devices to allow decryption of precision of observations. The SAASM hardware in AVs is a solution but it is expensive and its access is highly restricted.

In connected AVs, an additional major threat is the injection of fake messages that could trigger inappropriate reactions. Additionally, the authentication that protects the system from external attackers and misbehavior detection is required to detect internal and unintentional attacks. The deployment of malfunctioning detection systems requires not only a software update of the on-board unit (OBU) but also a major change in the current standardized security 
architecture such as the European Telecommunications Standards Institute (ETSI) or the American National Standards Institute's (ANSI) reference architecture. The OBU stores the content of all messages (new point of interest, obstacles, construction sites, etc.) in a so-called Local Dynamic Map (LDM in Europe) or Geographic Information System (GIS in the United States). Based on such a local representation of the real world, misbehavior detection, in-network data aggregation and more general decisions are made. Poisoning this database will affect the overall cooperative system. Here, again, the mitigation technique is a malfunctioning detection system, which performs plausibility checks before storing data into the map database.

Although priority has been given to the safety aspects of AVs, security has been largely overlooked [123]. Some cast doubt on the car manufacturers' commitments to protect cars against cybersecurity threats as such regulatory intervention becomes imperative [124]. The automotive industry needs to define a standardized approach that combines safety and security engineering. Conflicting requirements for privacy, safety, and security (and maybe other dependability attributes) need to be resolved during the design stage. The system "vehicle" is becoming a component of a "system of systems." As such, safety and security need to be integrated at the vehicle and system engineering level where the vehicle and the infrastructure are connected and intertwined. This is an enormous challenge and has already been taken up by other standardization committees for generic as well as domain specific standards. For instance, IEC $^{15} 61508$ [125] has already provided a first approach by integrating security requirements. Schoitsch et al. [126] suggest that security concerns can be integrated in ISO ${ }^{16} 26262$ ("Road vehicles Functional safety" [127]) for a combined safety and security standard.

In the quest to address security concerns pertaining to AV technology, we can learn from our counterparts in the avionics and high speed railway industries [126]. For instance, the approach was used to impose special conditions on type certificates for specific aircrafts. Nowadays, standards are merely developed for the specification of processes, methods, and instructions for continued airworthiness security. The same scheme should be adopted for AV technology.

\footnotetext{
15 IEC 61508 is an international standard published by the International Electrotechnical Commission of rules applied in industry. It is titled Functional Safety of Electrical/Electronic/Programmable Electronic Safety-related Systems (E/E/PE, or E/E/PES).

16 S O 26262 is an extension of IEC 61508 which defines Automotive Safety Integrity Levels (ASIL). ISO 26262 addresses the needs for an automotive-specific international standard that focuses on the safety of critical components.
}

Laws licensing, and regulations Technology and policies were unanimously assessed to be the most influential and unpredictable driving forces in the marketing of AVs [556]. According to Davidson and Spinoulas [128], trials are underway in a range of jurisdictions of at least 4 states in the U.S. (California, Michigan, Florida, Nevada); a number of European countries (including Germany, the UK, Spain, Belgium, Italy and France); as well as Australia, China, and Japan. In all of these cases, the laws set forth the parameters within which the testing of AVs can take place. Some require a human presence, i.e., someone who will be responsible for the operation of the vehicle. Insurance and liability issues (where the $\mathrm{AV}$ is tested on training grounds) are reasonably straightforward; however, the law becomes less clear when the AV is tested on public roads. The issue of ownership during the testing phase is clear as it will be that of the company developing the technology.

In order for $\mathrm{AVs}$ to achieve wide scale release on public roads, there will need to be considerable discussion and debate on a broad range of laws, not the least of which will include issues related to ownership, liability (the owner or the person in effective control), and insurance.

Key questions to be defined will include the following:

- In the case of an occupied vehicle where the "driver" is not in effective control, is the driver liable for an accident or the owner of the vehicle?

- In the case of an unoccupied vehicle, who is liable for an accident?

- Should comprehensive insurance become compulsory?

- In a situation where a pedestrian is injured by an unoccupied vehicle, who is at fault and who can the police charge with a crime?

- Will there be an offence such as negligent driving when negligence requires the actions of an individual and a mental element?

- Who will be responsible if the AV is used in the commission of a crime such as a bank robbery?

- Will the same laws apply to an occupied AV where the AV was not under the control of the occupant, yet the occupant is under the influence of alcohol or drugs, or is sleep deprived?

- Which Court will have jurisdiction to deal with matters pertaining to AVs, or will a special Court or Tribunal be established to deal with the specifics of this technology?

- The parameters of accident compensation insurance which compensates people for injuries sustained in motor vehicle accidents will need to be re-visited and substantial changes to this legislation may be required, including but not limited to the same issues above, where a vehicle is unoccupied. 
While the legal and insurance position may be somewhat clear (or as clear as is currently seen) in situations where the AV is "manned" or occupied, the waters are likely to be considerably muddier in situations where the $\mathrm{AV}$ is unmanned or unoccupied, as it then becomes a question of "who" is liable." Although AVs are accompanied by a wide range of benefits (regardless of occupancy), the social, legislative, and insurance challenges are significant [7].

\section{References}

1. Fagnant DJ, Kockelman K (2015) Preparing a nation for autonomous vehicles: opportunities, barriers and policy recommendations. Transp Res Part A 77:167-181

2. Guizzo E (2011) How google's self-driving car works. IEEE Spectrum Online, October 18

3. Markoff J (2010) Google cars drive themselves, in Traffic. New York Times 9

4. ACEA (2015) The automobile industry pocket guide. European Automobile Manufacturers Association, http://www.acea.be/ uploads/publications/POCKET_GUIDE_2015-2016.pdf

5. Nieuwenhuijsen J (2015) Diffusion of automated vehicles: a quantitative method to model the diffusion of automated vehicles with system dynamics. Delft University of Technology, TU Delft

6. Hong D, Kimmel S, Boehling R, Camoriano N, Cardwell W, Jannaman G, Purcell A, Ross D, Russel E (2008) Development of a semi-autonomous vehicle operable by the visually-impaired. In: IEEE International Conference on multisensor fusion and integration for intelligent systems, 2008. MFI 2008, pp. 539-544

7. Anderson JM, Nidhi K, Stanley KD, Sorensen P, Samaras C, Oluwatola OA (2014) Autonomous vehicle technology: A guide for policymakers. Rand Corporation

8. Folsom TC (2011) Social ramifications of autonomous urban land vehicles. In: IEEE International Symposium on Technology and Society

9. Piao J, McDonald M (2008) Advanced driver assistance systems from autonomous to cooperative approach. Transp Rev 28:659-684

10. Manyika J, Chui M, Bughin J, Dobbs R, Bisson P, Marrs A (2013) Disruptive technologies: advances that will transform life, business, and the global economy. McKinsey Global Institute New York

11. Petit J, Shladover SE (2015) Potential cyberattacks on automated vehicles. IEEE Trans Intell Transp Syst 16:546-556

12. Knight W (2013) Driverless cars are further away than you think. MIT Technology Review. https://www.technologyreview. com/s/520431/driverless-cars-are-further-away-than-you-think/

13. Litman T (2015) Autonomous vehicle implementation predictions. Victoria Transport Policy Institute 28

14. Maddox J, Sweatman P, Sayer J (2015) Intelligent vehicles + infrastructure to address transportation problems-a strategic approach. In: 24th international technical conference on the enhanced safety of vehicles (ESV)

15. Schoettle B, Sivak M (2014) A survey of public opinion about connected vehicles in the US, the UK, and Australia. In: 2014 International Conference on Connected Vehicles and Expo (ICCVE)
16. Kan Z, Qiang Z, Haojun Y, Long Z, Lu H, Chatzimisios $P$ (2015) Reliable and efficient autonomous driving: the need for heterogeneous vehicular networks. Commun Mag IEEE 53:72-79

17. Patriksson $P$ (1994) The traffic assignment problem: models and methods, VSP BV, The Netherlands. Facsimile reproduction published in 2014 by Dover Publications, Inc., Mineola

18. Sheffi Y (1985) Urban transportation networks: equilibrium analysis with mathematical programming methods. PrenticeHall Inc, Englewood Cliffs

19. Weber M (2014) Where to? a history of autonomous vehicles. Available at http://www.computerhistory.org/atchm/where-to-ahistory-of-autonomous-vehicles

20. Fenton RE, Mayhan RJ (1991) Automated highway studies at the ohio state university-an overview. IEEE Trans Vehicular Technol 40:100-113

21. Ioannou P (2013) Automated highway systems. Springer Science \& Business Media

22. Lantos B (2010) Nonlinear control of vehicles and robots. Springer Science \& Business Media

23. Blasch EP, Lakhotia A, Seetharaman G (2006) Unmanned vehicles come of age: The DARPA grand challenge. Computer 39:26-29

24. Google (2015) Google Self-Driving Car Project, http://static. googleusercontent.com/media/www.google.com/en//selfdriving car/files/reports/report-0615.pdf

25. Muir H (2016) Google self-driving car caught on video colliding with bus. In: (ed.) The Guardian https://www.theguardian.com/ technology/2016/mar/09/google-self-driving-car-crash-video-acci dent-bus

26. NHTSA (2013) http://www.nhtsa.gov/About \pm NHTSA/Press + Releases/U.S.+Department+of+Transportation+Releases + Policy+on+Automated+Vehicle+Development

27. Behere S, Törngren M (2015) A functional architecture for autonomous driving. In: Proceedings of the first international workshop on automotive software architecture. ACM, pp. 3-10

28. DiClemente J, Mogos S, Wang R (2014) Autonomous car policy report

29. Siciliano B, Khatib O (2008) Springer handbook of robotics. Springer Science \& Business Media, Berlin

30. Farhadi A, Endres I, Hoiem D, Forsyth D (2009) Describing objects by their attributes. In: IEEE Conference on Computer vision and pattern recognition, 2009. CVPR 2009, pp. $1778-1785$

31. Savasturk D, Froehlich B, Schneider N, Enzweiler M, Franke U (2015) A comparison study on vehicle detection in far infrared and regular images. In: IEEE 18th international conference on intelligent transportation systems (ITSC), IEEE 2015, pp. $1595-1600$

32. Chen W (2015b) Vehicular communications and networks: Architectures, protocols, operation and deployment. Elsevier

33. Sivaraman S (2013) Learning, modeling, and understanding vehicle surround using multi-modal sensing

34. Wei J, Snider JM, Kim J, Dolan JM, Rajkumar R, Litkouhi B (2013) Towards a viable autonomous driving research platform. In: Intelligent vehicles symposium (IV), IEEE 2013, pp. $763-770$

35. Link H, Nash C, Ricci A, Shires J (2014) A generalised approach for measuring the marginal social costs of road transport in Europe. Int J Sustain Transp, null-null

36. Parry IW, Walls M, Harrington W (2007) Automobile externalities and policies. J Econom Lit 45:373-399

37. Blincoe L, Miller TR, Zaloshnja E, Lawrence BA (2015) The economic and societal impact of motor vehicle crashes, 2010 (Revised) 
38. NHTSA (2012) 2010 motor vehicle crashes: overview. US Department of Transportation, Washington, DC, Research Note DOT HS 811, 552

39. IIHS (2010) New estimates of benefits of crash avoidance features on passenger vehicles, In: report, S. (Ed.), Insurance Institute for Highway Safety, pp. 4-5

40. Jermakian JS (2011) Crash avoidance potential of four passenger vehicle technologies. Accid Anal Prev 43:732-740

41. Farmer CM (2008) Crash avoidance potential of five vehicle technologies. Traffic Injury Prevention

42. Maddox J (2012) Improving driving safety through automation, congressional robotics caucus, National Highway Traffic Safety Administration

43. Davidson P, Spinoulas A (2015a) Autonomous vehicles-what could this mean for the future of transport?, AITPM 2015 National Conference

44. Greenblatt JB, Shaheen S (2015) Automated vehicles, on-demand mobility, and environmental Impacts. Curr Sustain Renew Energy Rep 2:74-81

45. Templeton B (2012) Where robot cars (robocars) can really take us. Brad Templeton Robocar Blog. Np http://www.templetons. com/brad/robocars/

46. Dresner K, Stone P (2004) Multiagent traffic management: a reservation-based intersection control mechanism. In: Proceedings of the Third international joint conference on autonomous agents and multiagent systems, 2004. AAMAS 2004, pp. $530-537$

47. Dresner KM, Stone P (2007) Sharing the Road: autonomous vehicles meet human drivers, IJCAI, pp. 1263-1268

48. Fajardo D, Au T-C, Waller S, Stone P, Yang D (2011) Automated intersection control: Performance of future innovation versus current traffic signal control. Transp Res Rec 1:223232

49. Martin EW, Shaheen S (2011) Greenhouse gas emission impacts of carsharing in North America. IEEE Trans Intell Transp Syst 12:1074-1086

50. Schoettle B, Sivak M (2015) Potential impact of self-driving vehicles on household vehicle demand and usage

51. Melis WJ (2014) The future of electrical vehicles. Autonomous Vehicles: Intelligent Transport Systems and Smart Technologies, 509-530

52. Kang N, Feinberg FM, Papalambros PY (2015) Autonomous electric vehicle sharing system design. In: ASME 2015 international design engineering technical conferences and computers and information in engineering conference. American Society of Mechanical Engineers, pp. V02AT03A034 V002AT003A034

53. Chen TD (2015a) Management of a shared, autonomous, electric vehicle fleet: vehicle choice, charging infrastructure $\&$ pricing strategies

54. Ploeg J, Serrarens AFA, Heijenk GJ (2011) Connect \& drive: design and evaluation of cooperative adaptive cruise control for congestion reduction. J Mod Transp 19:207-213

55. Fernandes P, Nunes U (2012) Platooning with IVC-enabled autonomous vehicles: strategies to mitigate communication delays, improve safety and traffic flow. IEEE Trans Intell Transp Syst 13:91-106

56. Milakis D, Snelder M, Van Arem B, Van Wee G, Homem de Almeida Correia G (2015) Development of automated vehicles in the Netherlands: scenarios for 2030 and 2050

57. Hensher DA, Bliemer MC (2014) What type of road pricing scheme might appeal to politicians? Viewpoints on the challenge in gaining the citizen and public servant vote by staging reform. Transp Res Part A 61:227-237

58. Shoup DC (2005) The high cost of free parking. Planners Press, Chicago
59. Sridhar KS, Sridhar V (2007) Telecommunications infrastructure and economic growth: evidence from developing countries. Appl Econom Int Dev 7

60. Alson J, Hula A, Bunker A (2014) Light-duty automotive technology, carbon dioxide emissions, and fuel economy trends: 1975 through 2013. Appendix F, US Environmental Protection Agency, Ann Arbor, Michigan. http://www.epa.gov/oms/ fetrends.htm\#report

61. NRC N.R.C. (2010) Hidden costs of energy: unpriced consequences of energy production and use. National Academies Press. doi: 10.17226/12794.

62. Atiyeh C (2012) Predicting traffic patterns, one Honda at a time. MSN Auto, June 25

63. Folsom T (2012) Energy and autonomous urban land vehicles. IEEE Technol Soc Mag 2:28-38

64. Lu X.-Y, Shladover SE (2014) Automated truck platoon control and field test, road vehicle automation. Springer, pp. 247-261

65. Brooker AD, Ward J, Wang L (2013) Light weighting impacts on fuel economy, cost, and component losses. SAE Technical Paper

66. US-DOE (2011) Report on the first quadrennial technology review. In: US Department of Energy. http://energy.gov/sites/ prod/files/QTR_report.pdf

67. US-EPA (2013) Light-duty automotive technology, carbon dioxide emissions, and fuel economy trends: 1975 through 2012, In: Agency UEP (ed.) Transportation and climate division, office of transportation and air quality. http://www.epa.gov/ fueleconomy/fetrends/1975-2012/420r13001.pdf

68. Bansal P, Kockelman KM (2016) Forecasting Americans' longterm adoption of connected and autonomous vehicle technologies. In: Transportation research board 95th annual meeting, no. 16-1871

69. Laslau C, Holman M, Saenko M, See K, Zhang Z (2014) Set autopilot for profits: Capitalizing on the $\$ 87$ billion self-driving car opportunity, In: http://www.giiresearch.com/report/ lux301508-set-autopilot-profits-capitalizing-on-87-billion.html

70. Kesting A, Treiber M, Helbing D (2010) Enhanced intelligent driver model to access the impact of driving strategies on traffic capacity. Philos Trans R Soc Lond A 368:4585-4605

71. Levin MW, Boyles SD (2016) A multiclass cell transmission model for shared human and autonomous vehicle roads. Transp Res Part C 62:103-116

72. Marsden G, McDonald M, Brackstone M (2001) Towards an understanding of adaptive cruise control. Transp Res Part C 9:33-51

73. Van Arem B, Van Driel CJ, Visser R (2006) The impact of cooperative adaptive cruise control on traffic-flow characteristics. IEEE Trans Intell Transp Syst 7:429-436

74. Carlino D, Depinet M, Khandelwal P, Stone P (2012) Approximately orchestrated routing and transportation analyzer: Largescale traffic simulation for autonomous vehicles. In: 15th international IEEE conference on intelligent transportation systems (ITSC), IEEE 2012, pp. 334-339

75. Levin MW, Boyles SD (2015) Intersection auctions and reservation-based control in dynamic traffic assignment. Transportation Research Record 1:35-44

76. Bagloee SA, Ceder A, Tavana M, Bozic C (2013) A heuristic methodology to tackle the Braess Paradox detecting problem tailored for real road networks. Transp A 10:437-456

77. Roughgarden T, Tardos É (2002) How bad is selfish routing? J ACM (JACM) 49:236-259

78. Bennett LD (1993) The existence of equivalent mathematical programs for certain mixed equilibrium traffic assignment problems. Eur J Oper Res 71:177-187

79. Harker PT (1988) Multiple equilibrium behaviors on networks. Transp Sci 22:39-46 
80. Yang H (1998) Multiple equilibrium behaviors and advanced traveler information systems with endogenous market penetration. Transp Res Part B 32:205-218

81. Bagloee SA, Ceder A, Bozic C (2014) Effectiveness of en route traffic information in developing countries using conventional discrete choice and neural-network models. J Adv Transp 48:486-506

82. Bagloee SA, Kermanshah M, Bozic C (2013) Assessment of public-private partnership in traveler information provision. Transp Res Rec 2394:19-29

83. van Essen M, Thomas T, van Berkum E, Chorus C (2016) From user equilibrium to system optimum: a literature review on the role of travel information, bounded rationality and non-selfish behaviour at the network and individual levels. Transp Rev 1-22

84. Aashtiani HZ (1979) The multi-modal traffic assignment problem. PhD dissertation, Massachusetts Institute of Technology

85. Bar-Gera H, Boyce D (1999) Route flow entropy maximization in origin-based traffic assignment. In: 14th international symposium on transportation and traffic theory. Elsevier Science, Oxford, U.K., Jerusalem, Israel, pp. 397-415

86. Boyce D (2014) Network equilibrium models for urban transport. In: Fischer MM, Nijkamp P (eds) Handbook of regional science. Springer, Berlin, pp 759-786

87. Chen BY, Lam WHK, Sumalee A, Shao H (2011) An efficient solution algorithm for solving multi-class reliability-based traffic assignment problem. Math Comput Model 54:1428-1439

88. Dafermos SC (1972) The traffic assignment problem for multiclass-user transportation networks. Transp Sci 6:73-87

89. Florian M, Morosan CD (2014) On uniqueness and proportionality in multi-class equilibrium assignment. Transp Res Part B 70:173-185

90. Nagurney A (2000) A multiclass, multicriteria traffic network equilibrium model. Math Comput Model 32:393-411

91. Nagurney A, Dong J (2002) A multiclass, multicriteria traffic network equilibrium model with elastic demand. Transp Res Part B 36:445-469

92. Xie J, Xie C (2014) An improved TAPAS algorithm for the traffic assignment problem. In: 17th international conference on intelligent transportation systems (ITSC), IEEE 2014, pp. 2336-2341

93. Xie J, Xie C (2015) Origin-based algorithms for traffic assignment: algorithmic structure, complexity analysis, and convergence performance. In; Transportation Research Board 94th annual meeting

94. Zhang G, Chen J (2010) Solving multi-class traffic assignment problem with genetic algorithm. In: Computational intelligence and natural computing proceedings (CINC), 2010 second international conference on. IEEE, pp. 229-232

95. Braess D (1968) Über ein Paradoxon aus der Verkehrsplanung. Unternehmensforschung 12:258-268

96. GAMS (2014) GAMS Development Corporation. GAMS Development Corporation, Washington DC

97. Chowdhury M, Dey K (2016) Intelligent transportation systemsa frontier for breaking boundaries of traditional academic engineering disciplines [Education]. IEEE Intell Transp Syst Mag 8:4-8

98. Sonka M, Hlavac V, Boyle R (2014) Image processing, analysis, and machine vision. Cengage Learning

99. Olson PL, Dewar R, Farber E (2010) Forensic aspects of driver perception and response. Lawyers \& Judges Publishing Company, Tucson

100. Wan Y, Huang Y, Buckles B (2014) Camera calibration and vehicle tracking: highway traffic video analytics. Transp Res Part C 44:202-213

101. Lillesand T, Kiefer RW, Chipman J (2014) Remote sensing and image interpretation. Wiley, New York
102. Alismail H, Browning B (2014) Automatic calibration of spinning actuated lidar internal parameters. J Field Robot 32:723-747

103. Shang E, An X, Wu T, Hu T, Yuan Q, He H (2015) LiDAR based negative obstacle detection for field autonomous land vehicles. J Field Robot

104. Bengler K, Dietmayer K, Farber B, Maurer M, Stiller C, Winner $\mathrm{H}$ (2014) Three decades of driver assistance systems: review and future perspectives. IEEE Intell Transp Syst Mag 6:6-22

105. Fleming B (2012) Recent advancement in automotive radar systems [Automotive Electronics]. Vehicular Technol Mag IEEE 7:4-9

106. Ilas C (2013) Electronic sensing technologies for autonomous ground vehicles: A review. In: 2013 8th international symposium on advanced topics in electrical engineering (ATEE), IEEE, pp. 1-6

107. Alonso L, Milanés V, Torre-Ferrero C, Godoy J, Oria JP, De Pedro T (2011) Ultrasonic sensors in urban traffic driving-aid systems. Sensors 11:661-673

108. Paromtchik IE, Laugier C (1996) Motion generation and control for parking an autonomous vehicle. In: Proceedings 1996 IEEE International conference on robotics and automation, IEEE 1996, pp. 3117-3122

109. Wang W, Song Y, Zhang J, Deng H (2014) Automatic parking of vehicles: a review of literatures. Int $\mathrm{J}$ Automot Technol 15:967-978

110. Mathas C (2016) The burgeoning use of sensors for advanced driver assistance systems. digikey.com, October 20, 2011. As of August 19, 2016: http://www.digikey.com/us/en/techzone/ sensors/resources/articles/the-burgeoning-use-of-sensors.html

111. John V, Mita S, Liu Z, Qi B (2015). Pedestrian detection in thermal images using adaptive fuzzy $\mathrm{C}$-means clustering and convolutional neural networks. In: 2015 14th IAPR international conference on. IEEE machine vision applications (MVA), pp. 246-249

112. Miura S, Kamijo S (2015) Gps error correction by multipath adaptation. Int J Intell Transp Syst Res 13:1-8

113. Dupuis Y, Merriaux P, Subirats P, Boutteau R, Savatier X, Vasseur P (2014) GPS-based preliminary map estimation for autonomous vehicle mission preparation. In: IEEE/RSJ international conference on intelligent robots and systems (IROS 2014), IEEE 2014, pp. 4241-4246

114. Tao Z, Bonnifait P (2014) Tightly coupling GPS with lane markings for autonomous vehicle navigation. In IEEE 17th international conference on intelligent transportation systems (ITSC), IEEE 2014, pp. 439-444

115. Britting KR (2010) Inertial navigation systems analysis. Wiley, New York

116. Velaskar P, Vargas-Clara A, Jameel O, Redkar S (2014) Guided navigation control of an unmanned ground vehicle using global positioning systems and inertial navigation systems. Int $\mathbf{J}$ Electr Comput Eng (IJECE) 4:329-342

117. Yang X, Liu J, Vaidya NH, Zhao F (2004) A vehicle-to-vehicle communication protocol for cooperative collision warning. In: Mobile and ubiquitous systems: networking and services, 2004. MOBIQUITOUS 2004. The First Annual International Conference on. IEEE, pp. 114-123

118. Gozálvez J, Sepulcre M, Bauza R (2012) IEEE 802.11 p vehicle to infrastructure communications in urban environments. Commun Mag IEEE 50:176-183

119. Kenney JB (2011) Dedicated short-range communications (DSRC) standards in the United States. Proc IEEE 99:1162-1182

120. Kumfer W (2015) Analysis of the effects of demographic and driver behavior variables on traffic safety and crash prediction. Texas Tech University 
121. Kumfer W, Burgess R (2015) Investigation into the Role of Rational Ethics in Autonomous Vehicle Crashes, Transportation Research Board 94th Annual Meeting

122. Pătraşcu A, Simion E, 2014. Cyber security evaluation of critical infrastructures systems, In: N., B., L., D., N.M., T. (eds.) Autonomous vehicles. Nova Science Publishers, Inc., pp. 185-205

123. Hussain M (2016) Security in connected cars. In: Proceedings of the European Automotive Congress EAEC-ESFA 2015. Springer, pp. 267-275

124. Schellekens M (2016) Car hacking: navigating the regulatory landscape. Comput Law Secur Rev 32:307-315
125. IEC (2010) IEC 61508, Functional safety of electrical/electronic/programmable electronic safety-related systems, parts 1-7, Ed. 2.0, IEC Std

126. Schoitsch, E., Schmittner, C., Ma, Z., Gruber, T., 2016. The need for safety and cyber-security co-engineering and standardization for highly automated automotive vehicles. In: Advanced microsystems for automotive applications 2015. Springer, pp. 251-261

127. ISO (2011) ISO 26262, International Standard 26262 Road vehicles-Functional safety

128. Davidson P, Spinoulas A (2015b) Autonomous vehicles-what could this mean for the future of transport? 